\title{
Preparation of needle coke from petroleum by-products
}

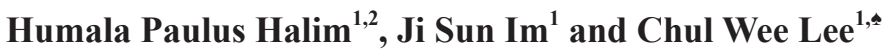 \\ ${ }^{1}$ Division of Green Chemistry and Engineering Research, Korea Research Institute of Chemical Technology, Daejeon 305-600, Korea \\ ${ }^{2}$ School of Science, University of Science and Technology, Daejeon 305-333, Korea
}

\section{Article Info}

Received 27 May 2013

Accepted 27 June 2013

*Corresponding Author

E-mail: chulwee@krict.re.kr

Tel: $+82-42-860-7381$

\section{Open Access}

DOI: http://dx.doi.org/

10.5714/CL.2013.14.3.152

This is an Open Access article distributed under the terms of the Creative Commons Attribution Non-Commercial License (http://creativecommons.org/licenses/ by-nc/3.0/) which permits unrestricted non-commercial use, distribution, and reproduction in any medium, provided the original work is properly cited.

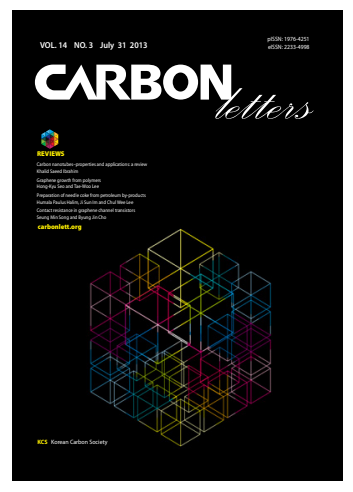

http://carbonlett.org

pISSN: 1976-4251

eISSN: 2233-4998

Copyright $\odot$ Korean Carbon Society

\begin{abstract}
Needle coke is an important material for graphite electrodes. Delayed coking is used to produce needle coke. Producing good quality needle coke is not simple because it is a multi-parameter controlled process. Apart from that, it is important to understand the mechanism responsible for the delayed coking process, which involves mesophase formation and uniaxial rearrangement. Temperature and pressure need to be optimized for the different substances in every feedstock. Saturate hydrocarbon, aromatic, resin and asphaltene compounds are the main components in the delayed coking process for a low Coefficient Thermal Expansion value. In addition, heteroatoms, such as sulphur, oxygen, nitrogen and metal impurities, must be considered for a better graphitization process that prevents the puffing effect and produces better mesophase formation.
\end{abstract}

Key words: needle coke, delayed coking, mesophase, aromatic, coefficient thermal expansion

\section{Introduction}

The petroleum industry has dominated the energy sector throughout the world. Many petroleum industries have expanded their explorations and increased their production to fulfill the demands for petroleum consumption across the world. Based on an Organization of the Petroleum Exporting Countries (OPEC) report, production of crude oil in the world increased from 68984700 barrels per day in 2009 to 70436700 barrels per day in 2011 [1]. From this large quantity of petroleum production, it is undeniable that a large quantity of by-products has been produced as well.

This large quantity of by-products has the potential to be processed or utilized to become more valuable products such as needle coke for graphite. A calcined form of needle coke can become raw material to produce graphite electrodes that can be used in electric arc steel furnaces [2]. It has been determined that demand of graphite has increased each year and will continue to increase until 2014 as shown in Fig. 1.

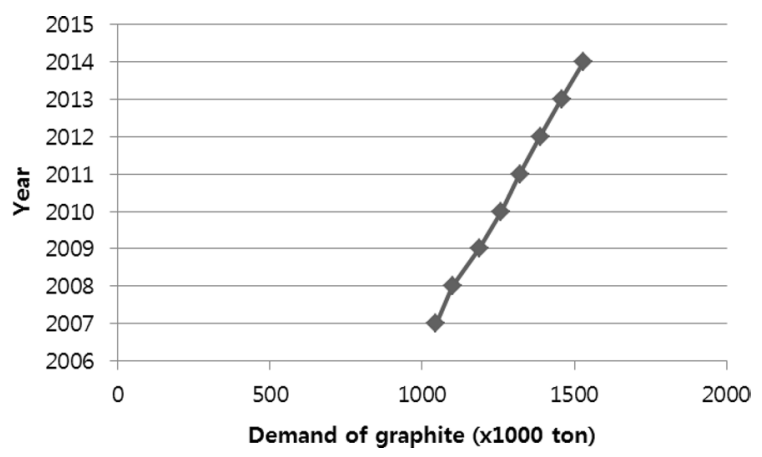

Fig. 1. Data of global demand of graphite 2007-2014 [3]. 
Table 1. Types of needle coke [4]

\begin{tabular}{cccc} 
& $\begin{array}{c}\text { Ultra premium } \\
\text { needle coke }\end{array}$ & $\begin{array}{c}\text { Super premium } \\
\text { needle coke }\end{array}$ & $\begin{array}{c}\text { Intermediate } \\
\text { premium } \\
\text { needle coke }\end{array}$ \\
\hline $\begin{array}{c}\text { CTE value, } \\
10^{-6}{ }^{\circ} \mathrm{C}\end{array}$ & 0.25 & 0.35 & 0.6 \\
\hline $\begin{array}{c}\text { Sulfur con- } \\
\text { tent, wt } \%\end{array}$ & - & $0.2-0.4$ & $0.4-0.6$ \\
\hline $\begin{array}{c}\text { V/Ni content, } \\
\mathrm{mg} / \mathrm{kg}\end{array}$ & - & $<10$ & $<10$ \\
\hline $\begin{array}{c}\text { Real density, } \\
\mathrm{g} / \mathrm{cm}^{3}\end{array}$ & - & $2.13-2.15$ & $2.13-2.14$ \\
\hline $\mathrm{H}$ content & - & $0.03-0.05$ & $0.03-0.05$ \\
\hline
\end{tabular}

CTE: coefficient of thermal expansion.

Needle coke is a specific type of coke with a high level of graphite resulting from its microcrystalline structure. A high level of anisotropy, large crystallite size and large crystal areas must be achieved in order to obtain good quality needle coke [4]. Feedstock selection and a delayed coking condition are crucial processes that need to be optimized. The quality analysis of needle coke can be specified on the basis of the coefficient of thermal expansion (CTE) value as listed in Table 1.

The CTE value is an important characteristic of coke when it is used for measuring the effect of sudden thermal shock. It is the ability to dissipate thermal energy to avoid causing physical deformation [5]. In a practical way, it can dissipate thermal energy without cracking on carbon. Marsh et al. [6] defined a low CTE value for highly ordered anisotropic carbon since it dissipates energy without cracking due to thermal shock. Subsequently, less ordered carbon (isotropic) has a high CTE value. When it experiences thermal shock, its layers expand against one another. Hence, cracking occurs due to mechanical stress [6].

Delayed coking is a process for producing coke by transforming a complex mixture of aromatics to solid carbon as shown in Fig. 2. It provides thermal energy to form a mesophase of the precursor during carbonization [6]. In carbonization, thermal cracking, thermal polymerization, condensation and dealkylation occur [7]. When starting materials are thermalized, cross-linkages are broken and polymerized aromatic molecules form liquid crystal and then adjacent liquid crystals coalesce [8]. The liquid crystals are transformed with an increase of temperature for a certain time [9]. Thus, the material continues to calcination to stabilize the coke by a temperature of around $1000^{\circ} \mathrm{C}$. It possesses solid concentrated carbon by dehydrogenation or removal of chemical bound hydrogen [10].

According to Ashish's definition (2007), when residue is heated, its pendant chains separate and weak links break and combine to form larger units with a high $\mathrm{C} / \mathrm{H}$ ratio. Formations of graphite-like structures and distillate were hypothesized to form by clustering of aromatic free radicals and cracking of aliphatic linkages, respectively, [11] as sketched in Fig. 2a. In addition, Mochida [12] analyzed carbonization model acenaph-

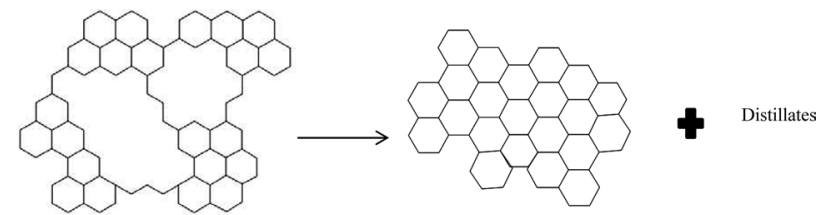

(a)
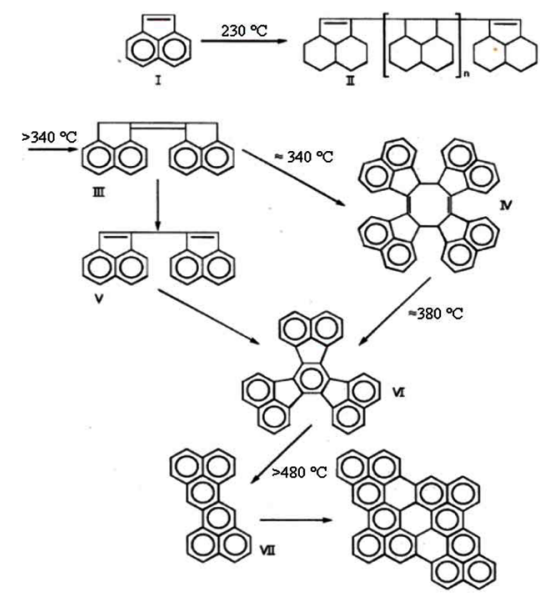

(b)

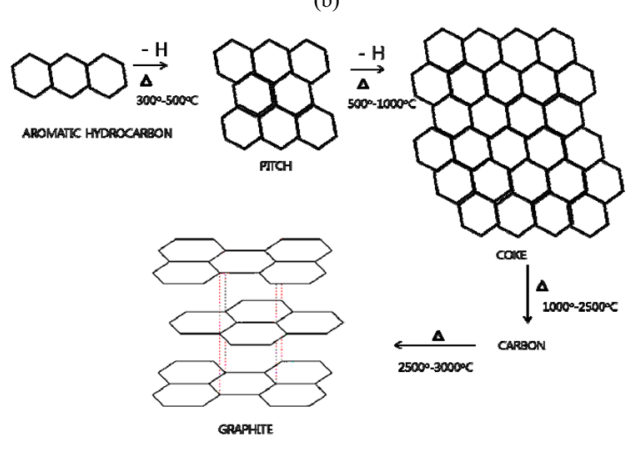

(c)

Fig. 2. Sketches of coke formation from various aromatic compounds [11-13].

thylene (I) as shown in Fig. 2b. Acenaphthylene forms large optical anisotrophy when it is thermal treated at low temperature [12]. This analysis suggests a small constituent at the carbonization step can have an effect on the coke properties. Another scheme of reaction in mesophase formation was suggested by Lewis [13] and involved using anthracene. The reaction follows free radicals induced by thermal polymerization and condensation as described in Fig. 2c.

\section{Feedstock selection}

Fig. 2 describes clearly the process of coke formation and confirms that aromatic molecules play an important role in it. It has also been mentioned that characteristics of feedstock are crucial to producing needle coke. Different substances of feedstock determine the quality of needle coke. Other compounds, such as saturates, resins, asphaltenes, sulphur, oxygen, nitrogen, and impurities, can affect the quality of needle coke [14-16].

Aromatics have a simple structure relative to resins and 


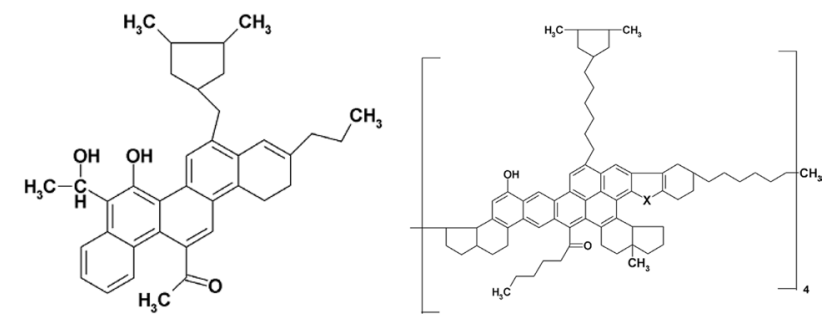

Fig. 3. Resin structure of American crude oil (left) and Turkish bitumen (right) [24].

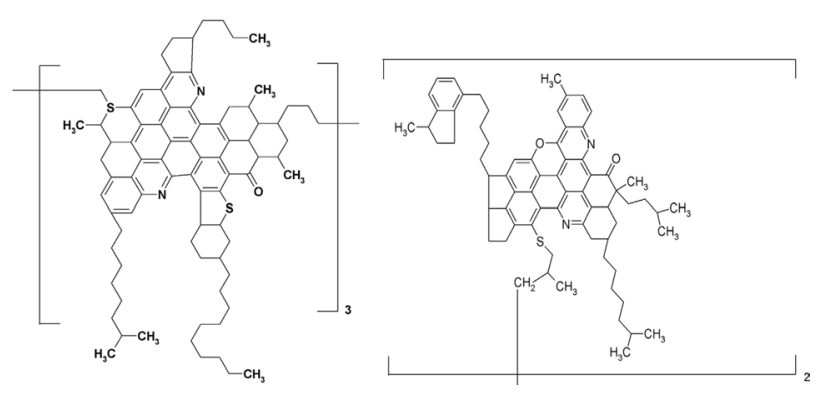

Fig. 4. Asphaltene structure of Venezuelan (left) and Californian crude oil (right) [24].

asphaltenes [17]. Even though aromatic molecules are desirable, it does not mean that all kinds of aromatic compounds support the development process of needle coke. Alkyl side chains bound to aromatic compounds suggest deeper observation of aromatic compounds. It has been found that molecular composition of feedstock affects mesophase development [18]. Multimethyl-substituted polyaromatic hydrocarbons are detected by gas chromatography-mass spectrometry (GC/ MS) on light fraction and high pressure liquid chromatography-mass spectrometry (HPLC/MS), laser desorption-mass spectrometry (LD/MS) on heavy fraction. Carbonization reactivity is related to the number of the alkyl chains. A high degree of alkylation on polyaromatic hydrocarbon produces a low degree of mesophase development upon carbonization [18]. In addition, naphthenic rings are an important parameter in controlling the carbonization process in terms of mesophase development. Its hydrogen transfer ability to molecular constituents is favorable for stabilization allowing development of flow texture [19].

Saturate compounds, which consist of straight chain paraffins and long alkyl chains of aromatic rings, take a role in the solidification step, especially in the uniaxial rearrangement of the bulk mesophase. It is preferable to be at least 5 parts by weight with respect to 100 parts by weight of aromatic components and at least $3 \mathrm{wt} \%$ with respect to the total weight of crude oil composition $[20,21]$. In term of the coking process, there are two major steps of needle coke formation in the carbonization process. First, it is bulk mesophase formation of low viscosity through nucleation, growth and coalescence of mesophase spheres. The second step is uniaxial rearrangement of the bulk mesophase by aid of gas evolution [14,22]. In solidification stage, saturate compounds become the source of gas evolution in reordering molecules uniaxially.

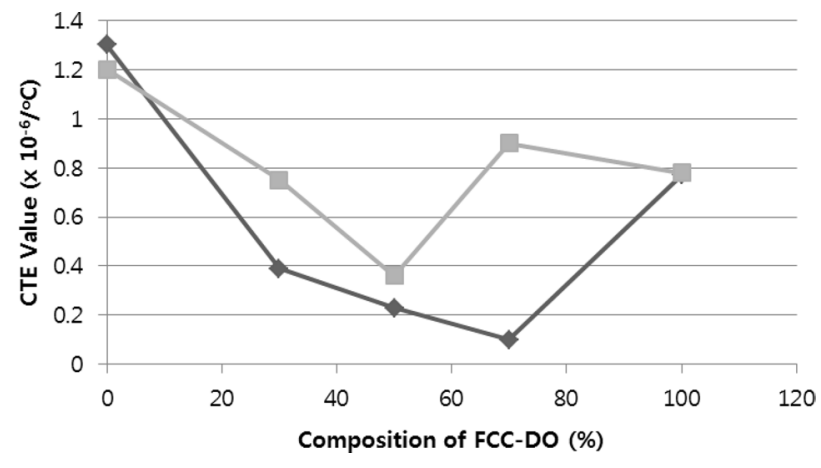

Fig. 5. Composition of FCC-DO to CTE value at temperature of $480^{\circ} \mathrm{C}$ and $460^{\circ} \mathrm{C}(\square)$ [27]. CTE: coefficient of thermal expansion, FCC-DO: fluid catalytic cracking-decant oil.

An investigation was carried out by Song and Cheng [23] related to the effect of the quantity of alkyl groups on needle coke formation. Increasing alkyl groups results in promoting flow texture that leads to a low CTE value [23].

Resin compounds consist of partial aromatics and paraffin chains. In some cases, chemical structures of resin are different as figured in Fig. 3. It shows resin compounds consisting of undesirable heteroatoms and two-thirds aromatic carbon. Its complex structure and undesirable content needs to be considered further to treat it as a desirable compound.

Asphaltene compounds have been recognized as having a heavy molecular weight with high heteroatoms and aromatics [25] as shown in Fig. 4. It has been proven that asphaltene has high reactivity and an ability to increase the rate of carbonization $[26,27]$. It is likely to form isotropic mosaic to coke formation that leads to a high CTE value [26-28].

To better understand the influence of these compounds, many experiments have been commonly made from high aromatic compounds with a low sulphur content, such as fluid catalytic cracking-decant oil (FCC-DO) and high asphaltene content of vacuum residue. Occasionally, they are blended or mixed, that is, co-carbonization, to study reactivity of asphaltene and other compounds in the process of producing needle coke [27-29].

FCC-DO has a moderate molecular size according to content of alkyl groups and naphthenic hydrogen [30]. Aromatic and naphthenic rings are favored for performing mesophase growth while hydrogen transfer of naphthenic rings is favored for arranging well-oriented flow texture in coke [31-34]. Long alkyl side chains, oxygen, sulphur functional groups are unfavorable because they can hamper mesophase growth, as do excessive size of aromatic rings [22].

On the other hand, vacuum residue, which is produced as a residue product of vacuum distillation, generally contains higher sulphur and asphaltene than other feedstocks. Low sulphur vacuum residue (LSVR) carries high-reactive asphaltene $[28,29]$ due to its large molecular weight of aromatic nucleus, many alkyl side chains and micelle aggromelation [27]. LSVR is not the best candidate to be produced for needle coke [14]. Besides, it results in a thick mosaic coke with a mesophase of low viscosity which is also difficult to be met because the paraffinic fraction in LSVR is poor as a solvent for asphaltene fraction [27]. 


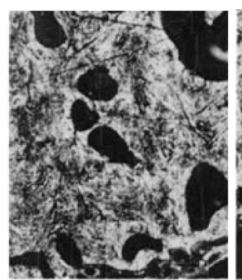

FCC-DO

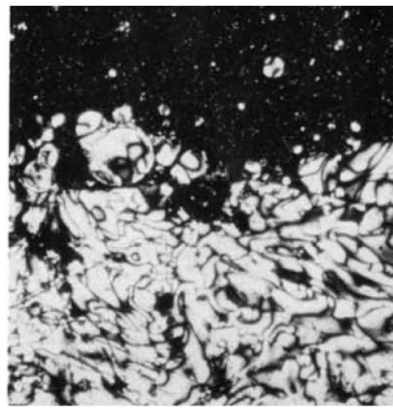

FCC-DO

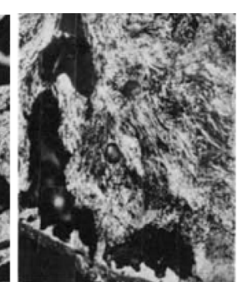

FCC-DO $(70 \%)$

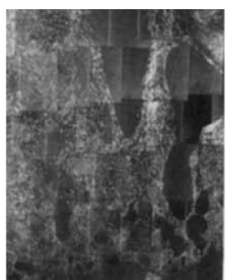

LSVR

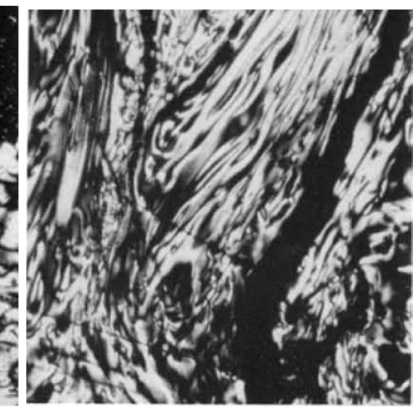

FCC-DO (70\%)
Fig. 6. Photographs of cokes with various composition of FCC-DO [27] up; [35] bottom. FCC-DO: fluid catalytic cracking-decant oil, LSVR: low sulphur vacuum residue.

However, addition of slight LSVR into FCC-DO (co-carbonization) can increase the length of anisotropic units and improve the flow texture, which leads to improved CTE values as shown in Fig. 5 [27,35]. It can accommodate carbonization of FCC-DO in producing an excellent bulk mesophase of low viscosity [3638]. Co-carbonization can control the high reactivity and solubility to form a better mesophase.

Aromatic compounds play an important role in producing needle coke, so FCC-DO is commonly used. Methyl groups of FCC-DO attached to an aromatic ring produces gas evolution giving excellent needle coke [39]. Not only with FCCDO, gas evolution also results from LSVR because LSVR contains non-carbonized aromatic, alkyl side chains and straight chains paraffin. An aromatic component of FCC-DO can also dissolve an asphaltene fraction resulting in a smaller amount of bottom mosaic coke as illustrated in Fig. 6. This co-carbonization provides more gas evolution and reduces bottom mosaic coke and mesophase formation. This cooperation influences the reactivity, solubility and hydrogen-donating ability [30,39].

There are two groups of heteroatoms content: heteroatoms bound as heterocyclics and functionalities to aromatic. The heterocyclics can be furan, thiophenes or pyridines. Thus, functionalities to aromatic can be hydroxyls, thiols and amides.

One of the heteroatoms, sulphur, is important criterions for needle coke application in making electrodes [40]. The preferred maximum sulphur concentration for needle coke is $1 \%$ [41]. C-S bonds have high thermal stability even at calcination temperatures up to $1350^{\circ} \mathrm{C}$. When the temperature is elevated to $1400^{\circ} \mathrm{C}$ and $1500^{\circ} \mathrm{C}$, the bonds break out and cause puffing. In-process electrodes will be cracked and weakened. The excess heat destroys the structural integrity of the carbon body [42]. Because of that, an extended time is required for the graphitization process to minimize the cause of the puffing effect and it consumes

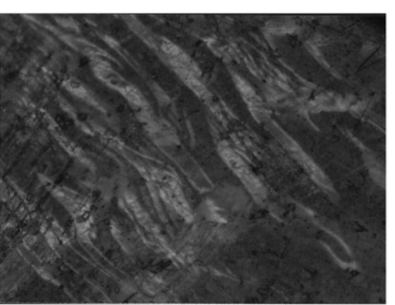

Without $\mathrm{Fe}_{2} \mathrm{O}_{3}$

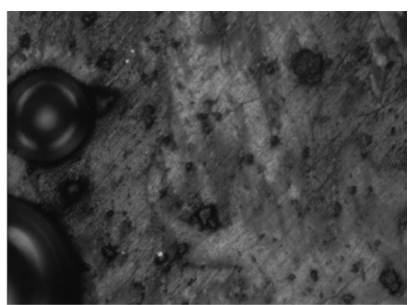

Concentration $\mathrm{Fe}_{2} \mathrm{O}_{3} 6 \%$
Fig. 7. Comparison of optical texture of mesophase development with and without presence of $\mathrm{Fe}_{2} \mathrm{O}_{3}[47]$.

much energy [2].

Other heteroatoms, such as nitrogen and oxygen, need to be considered as well. Investigations have found that nitrogencontaining polyaromatic hydrocarbons, such as carbazole and phenazine, result in mosaics and hamper the mesophase development [43]. In addition to nitrogen, oxygen-containing aromatics have been investigated as well to be able to form isotropic microstructures. Hydroxyl functions such as phenolic compounds increase viscosity and form isotropic mosaics $[43,44]$.

According to Kuchhal [40], impurities such as metals take part in affecting the properties of coke. $\mathrm{Ni}, \mathrm{V}$ and $\mathrm{Fe}$ affect its mechanical strength and resistivity. Moreover, they inhibit the working system of the coke, especially for graphite electrode application. Vanadium in coke can cause oxidation leading to an increase in consumption of the electrode. When a graphite electrode is used as an anode in chlorine-alkaline, vanadium can reduce hydrogen and the hydrogen will enrich chlorine. For further or higher concentration of vanadium, there is a danger of explosion due to chlorine/hydrogen gas formation [40]. There are still many investigations being conducted on the effect of metals contained in the feedstock or used as catalysts in the carbonization process.

Effects of impurities were investigated by Obara et al. [45]. When silica gel was added to FCC-DO, it reduced transferable hydrogen in the carbonization process and microstructure of coke [45]. In addition, Marsh et al. [46] demonstrated the effect of metal ( $\mathrm{Li}, \mathrm{Na}, \mathrm{K}, \mathrm{Rb}, \mathrm{Cs}$ ) hydroxides and carbonates to pitch leading to formation of isotropic carbon.

On the other hand, Wang et al. [47] obtained fine mosaic microstructures of coke due to effect of iron oxide. When the cokes resulted with and without iron oxide additive were compared, the coke without iron oxide additive exhibited better quality of formation of anisotropic as described in Fig. 7. It showed formation of an anisotropic flow texture while coke with iron oxide additive improved development of a mosaic texture [47]. This determines the effect of iron oxide as a barrier to mesophase development. However, this effect of iron oxide is disparate with Boudou et al.'s [48] experiment by iron chloride to coal tar pitch. Addition of iron chloride caused speeding up the mesophase growth due to effects of Lewis acid.

A similar case of the effects of iron compound on mesophase development was investigated by Song et al. [49]. The result was in agreement with Boudou et al. [48] supporting iron compound to mesophase growth. When concentration of ferrocene 
was increased, mesophase spheres became larger and grew into a coalesced mesophase [49] as shown in Fig. 8. It indicates the behavior of formation of mesophase proportioned by concentration of ferrocene.

In addition, other compounds, such as titanium, can enhance mosaic structure. Ramos-Fernandez et al. [50] used two dif-

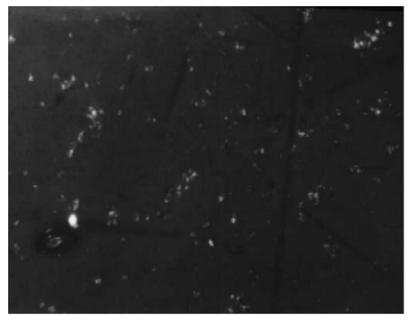

Without ferrocene

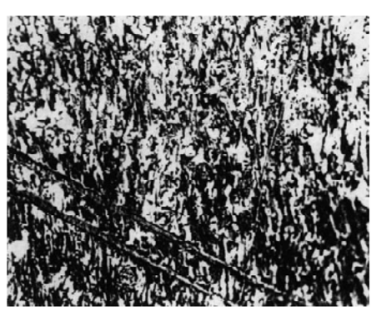

Ferrocene $(10 \%)$

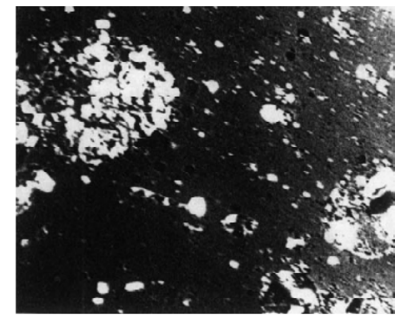

Ferrocene (3\%)

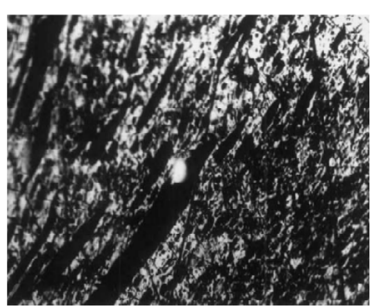

Ferrocene $(20 \%)$

Fig. 8. Comparison of optical texture of mesophase development to concentration of ferrocene [49].

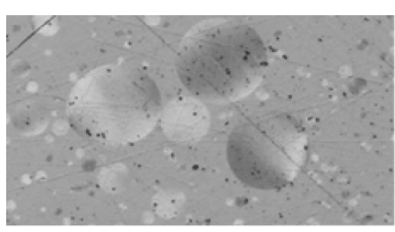

Without TBO and TC

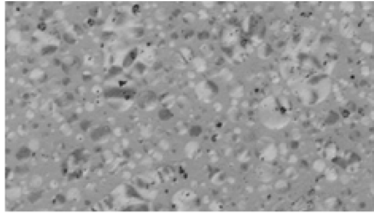

$1 \%$ concentration of TBO

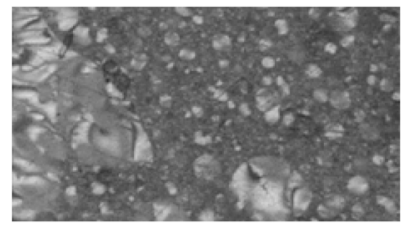

$1 \%$ concentration of TC

Fig. 9. Comparison of optical texture of mesophase growth with and without presence of TBO and TC [50]. TBO: tetrabutyl-ortotitanate, TC: titanium carbide.

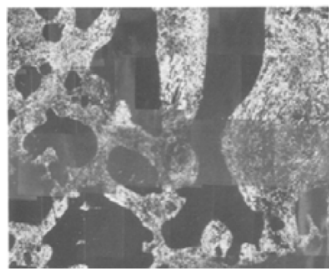

$\left(500^{\circ} \mathrm{C}\right)$

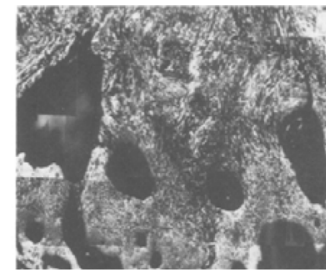

$\left(480^{\circ} \mathrm{C}\right)$ ferent sources of titanium, tetrabutyl-ortotitanate (TBO) or titanium carbide (TC) nano-powder, to investigate the effects of titanium on mesophase behavior. Abundant mesophase spheres were observed, but they didn't coalesce easily as shown in Fig. 9 [50]. Hence, a mosaic structure developed and rearrangement for flow texture was difficult as well.

\section{Delayed coking conditions}

It has been mentioned that every starting material has different substances that lead to different operating conditions. The operating conditions need to be optimized, such as the temperature and pressure, to achieve sophisticated quality needle coke. They are relative to the reactivity of the feedstock or its chemical composition.

\subsection{Temperature to quality of needle coke}

It has been confirmed that temperature influences the quality of needle coke [51]. When LSVR was carbonized within $440-500^{\circ} \mathrm{C}$ in a tube bomb [14], a series of optical textures of the needle coke was obtained. Needle cokes produced at $480^{\circ} \mathrm{C}$ and $460^{\circ} \mathrm{C}$ had fewer pores than those of needle coke produced at $500^{\circ} \mathrm{C}$. However, it only had a little mosaic texture in the bottom. Mosaic texture is undesirable in needle coke. Being compared with results of $500^{\circ} \mathrm{C}$ and $440^{\circ} \mathrm{C}$, the mosaic texture was more dominant. Other cases of mosaic coke can be found in experiment [27] as well as shown in Fig. 10.

In addition, a temperature at $460^{\circ} \mathrm{C}$ resulted in a higher degree of uniaxial arrangement of the flow texture than other temperatures. The anisotropic texture of the needle coke at $460^{\circ} \mathrm{C}$ was well-developed and oriented in a direction parallel to the axis as shown in Fig. 10. The gas evolution at $500^{\circ} \mathrm{C}$ increased rapidly and overlapped its maximum limit. This overlapped gas evolution changed the the coke texture became arranged in a random manner. A rapid carbonization allows precipitation of condensed product to form bottom mosaic coke [14].

Since high temperature is completes the carbonization process for mesophase growth very rapidly, a lower temperature is preferable. It allows a longer time for mesophase growth and more rapid coalescence into a bulk mesophase [27]. However, low temperature is also not favorable because of low solubility: Gas evolution is much delayed and misses the time for solidification causing failure of the uniaxial arrangement of the bulk mesophase.

Other measurements, such as CTE value, can be exactly es-

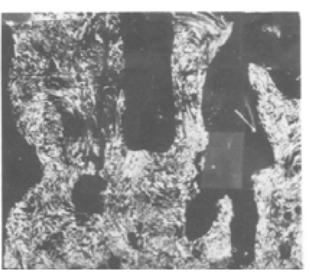

$\left(460^{\circ} \mathrm{C}\right)$

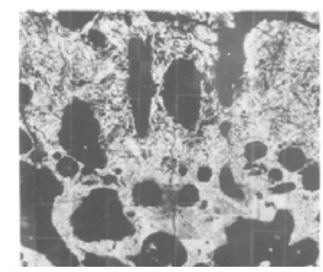

$\left(440^{\circ} \mathrm{C}\right)$

Fig. 10. Montage photographs of cokes produced at different temperatures in the experiment [14]. 


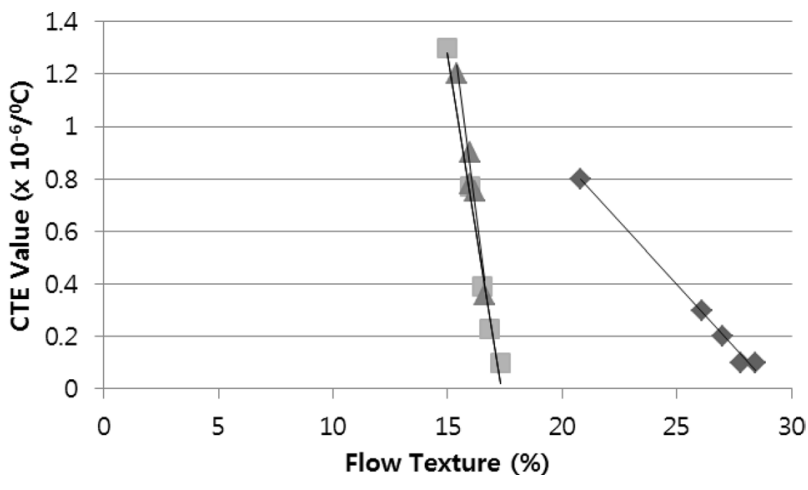

Fig. 11. Correlation of flow texture and coefficient of thermal expansion (CTE) value at temperature of $480^{\circ} \mathrm{C}(\boldsymbol{\square}), 460^{\circ} \mathrm{C}(\mathbf{\Delta})$ [27] and $490^{\circ} \mathrm{C}$ $(\diamond)$ [49].

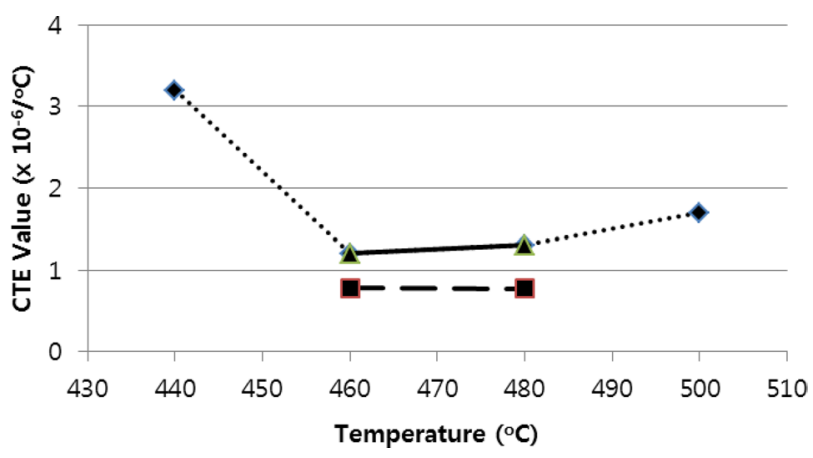

Fig. 12. Experimental data of coefficient of thermal expansion (CTE) value to temperature of carbonization for experiment 1 ( $\$$ [14], experiments $2(\square)$ and $3(\mathbf{\Lambda})[27]$.

timated by the behavior of the uniaxial arrangement of the flow texture. It is principally related to the uniaxial arrangement of the graphite layers and microcracks among the graphite grains. It was evaluated by Mochida et al. [34,52] by plotting CTE values of the coke against the contents of flow texture. Fig. 11 describes the linear correlation between the uniaxial arrangement and the CTE value.

In terms of the CTE value in the experiment [14], the optimum temperature for carbonization of the LSVR is $460^{\circ} \mathrm{C}$. It represents the lowest CTE value $1.2 \times 10^{-6} /{ }^{\circ} \mathrm{C}$ specifically among 4 temperatures as shown in the experimental data of Fig. 12.

The above data confirms that carbonization for needle coke with a low CTE value and the resultant bottom mosaic coke is not a simple process only depending on high temperature. An adequate temperature of carbonization is needed to achieve high quality needle coke. The temperature must be controlled to be neither too high nor too low.

\subsection{Pressure effect on the quality of needle coke}

It has been observed that change of pressure affects the quality of needle coke. Behavior of changing pressure is likely similar to changing temperature. There is no certain evidence that increasing pressure will result in excellent quality needle coke. Low pressure tends to increase the CTE value and decrease the flow texture, but high pressure can result in a low CTE value, good flow structure and mosaic coke reduced $[27,28]$.

According to Table 2, changing the pressure over and under 1.5 MPa influences the CTE value. It must be considerable for lowering pressure to less than 1.5 MPa since it is not effective and causes an increasing CTE value as shown from samples A and B. Hence, high pressure is needed to lower the CTE value. In addition, samples $H$ and I show improvement in mosaic coke. Although the uniaxial arrangement of flow texture is slightly defective due to an increase in pressure, the mosaic coke gets thinner. However, increasing pressure over $4 \mathrm{MPa}$ needs to be considered as well. Sample F shows an increasing CTE value while it contains more flow texture than before. It demonstrates carbonization pressure unable to be simply controlled due to strong influences of the substance itself [53-55].

It is very important to understand the detailed production process of needle coke. It has been mentioned that there are two major steps in needle coke formation in the carbonization process. First, it is bulk mesophase formation with low viscosity through nucleation, growth and coalescence of mesophase spheres. The second step is uniaxial rearrangement of the bulk mesophase by aid of gas evolution at solidification of mesophase into coke [14,22].

On this basis, the conditions of the process can be controlled for low cost and more effectiveness. Operation conditions can be processed separately. To achieve sophisticated results of needle coke, the second step does not have to be the same as the first process.

This method has been applied from different points of view [56,57]. Mochida et al. [56] investigated pressure reductions in the second step with LSVR. The pressure was reduced from 1.5 $\mathrm{MPa}$ to $0.7 \mathrm{MPa}$ with different rates of pressure. Different results were obtained between with pressure reduction and without pressure reduction. Carbonization without pressure reduction was similar to that of pressure reduction with a rate of 0.1 $\mathrm{MPa} / \mathrm{min}$ as shown in Fig. 13. The rate of pressure reduction of $0.3 \mathrm{MPa} / \mathrm{min}$ and $0.7 \mathrm{MPa} / \mathrm{min}$ produced excellent flow textures and was well-oriented.

Timing is the most critical for this method. Insufficient time of carbonization in the first step results in a lack of the bulk mesophase. Every feedstock has its own critical time to form mesophase spheres and grow to mesophase [35]. Furthermore, a small rate of pressure reduction must be considered since it will fail to concentrate gas evolution for rearrangement at solidification [56].

On the other hand, Jieming et al. [57] used the same mechanism to produce needle coke at low pressure. The first step was conducted with $400^{\circ} \mathrm{C}$ and $0.35 \mathrm{MPa}$ for $5 \mathrm{~h}$ [57]. This step was analyzed by H-NMR and it was found that the aromatic fraction increased, which influenced the mesophase [58]. In addition, it increases the short-branches of aromatic by cracking long-chain branches leading to directional arrangement of the mesophase. However, it consumes too much time for the second step (around $24 \mathrm{~h}$ ) due to the low pressure used in the first step. High pressure in the first step is favored for better development of a bulk mesophase [56]. 
Table 2. Change of pressure to CTE value and montage photographs of cokes produced at temperature $500^{\circ} \mathrm{C}$ (samples A-G) $[28]$ and $480^{\circ} \mathrm{C}$ (samples $\mathrm{H}-\mathrm{I})$ [27]

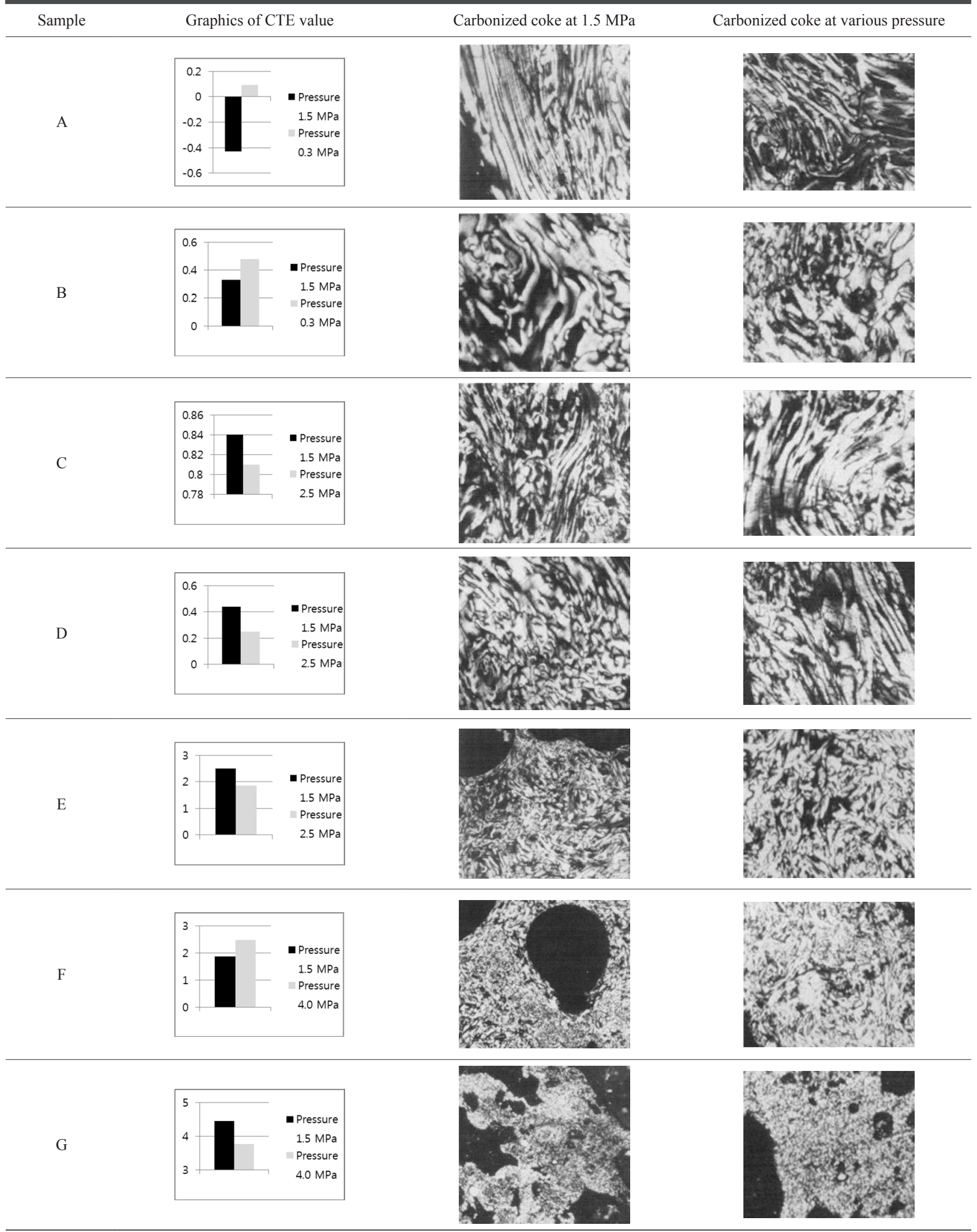




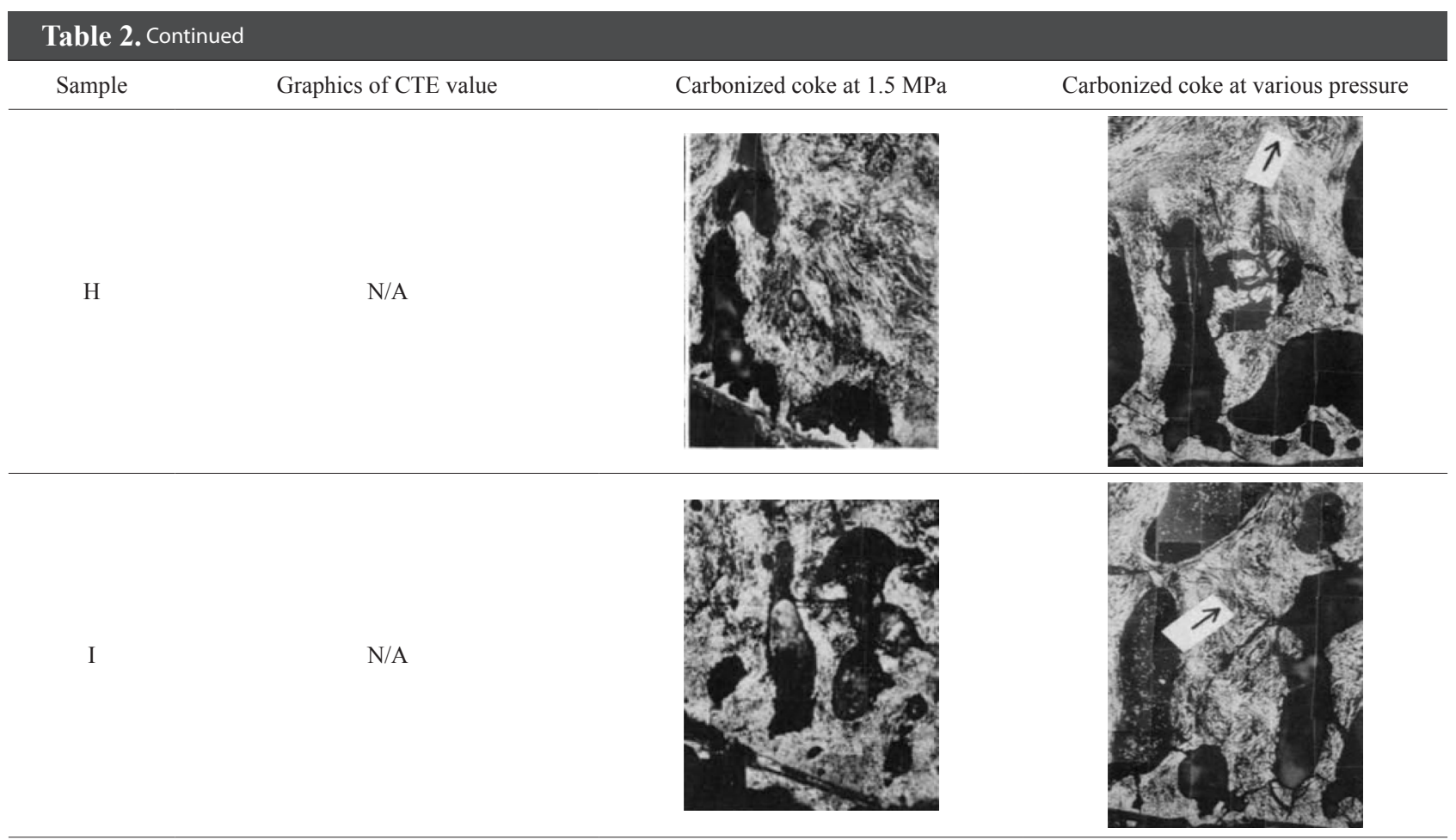

CTE: coefficient of thermal expansion, N/A: not applicable.

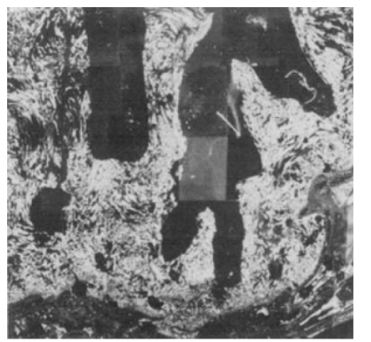

No pressure reduction

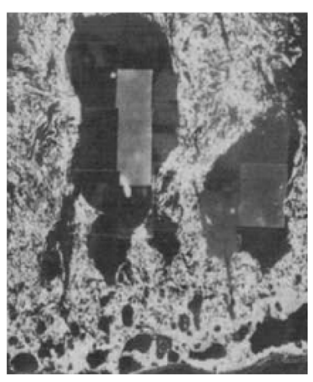

Rate of pressure reduction $0.7 \mathrm{MPa} / \mathrm{min}$

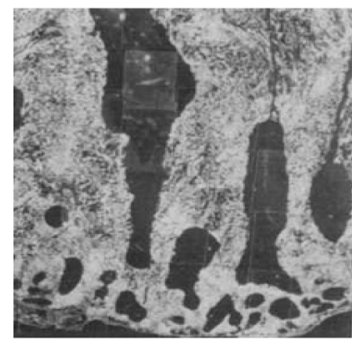

Rate of pressure reduction $0.1 \mathrm{MPa} / \mathrm{min}$

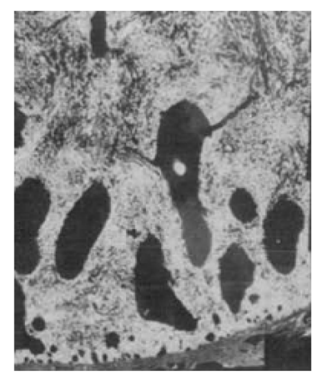

Rate of pressure reduction $0.3 \mathrm{MPa} / \mathrm{min}$

Fig. 13. Montage photographs of coke produced with and without pressure reduction at different rate [56].

\section{Conclusions}

Needle coke is an important material for producing graphite electrodes in electric arc steel furnaces. Since the demand for graphite electrodes increases each year, production of needle coke must increase as well. The process for making coke is called delayed

coking. In order to achieve excellent quality needle coke, two major steps are needed. The first step is the coalescence of the mesophase to its formation. The second step is rearrangement of the mesophase in the solidification stage. It is important to analyze the properties of the feedstock to balance the process. Aromatic and saturate compounds play an important role since aromatic compounds determine the mesophase formation and saturate compounds are favorable for gas evolution in the solidification stage. Resin and asphaltene compounds are undesirable due to the existence of heteroatoms. They can inhibit the process of mesophase development and cause the puffing effect in graphitization. Impurities such as iron oxide and titanium were proven to inhibit formation of the mesophase and develop a mosaic structure. In addition, the operating conditions such as temperature and pressure have to be controlled in the delayed coking process. High temperature and pressure do not always result in good quality needle coke. It is necessary to follow the major steps since substances of feedstock are different from one place to another place. Mixing two kinds of feedstock can become an effective process to increase the quality of needle coke. For example, FCC-DO has an aromatic compound and LSVR has an asphaltene fraction that can enhance mesophase formation and mosaic coke. However, a small amount of LSVR can provide excellent mesophase cooperatively by generating gas evolution.

\section{References}

[1] Organization of the Petroleum Exporting Countries (OPEC). World crude oil production by country. Ann Stat Bull, 30 (2012).

[2] Acciarri JA, Stockman GH. Demand for superpremium needle cokes on upswing. Oil Gas J, 87, 118 (1989).

[3] StratMin Global Resources Plc. Introduction to Graphite Produc- 
tion in Madagascar, StratMin Global Resources Plc, London, UK (2013). Available from: http://www.proactiveinvestors.co.uk/genera/files/companies/stratmin_3.pdf.

[4] Predel H. Petroleum coke. In: Bohnet M, ed. Ullmann's Encyclopedia of Industrial Chemistry. 7th ed., Wiley-VCH, Weinheim, 361 (2012).

[5] ASM International. Thermal expansion. In: Cverna F, ASM International. Materials Properties Database Committee, eds. ASM Ready Reference Thermal Properties of Metals, ASM International, Materials Park, OH, 9 (2002).

[6] Marsh H, Heintz EA, Rodriguez-Reinoso F. Introduction to Carbon Technologies, Universidad de Alicante, Alicante, Spain, 491, 496, 521 (1997).

[7] de Castro LD. Anisotropy and mesophase formation towards carbon fibre production from coal tar and petroleum pitches - a review. J Braz Chem Soc, 17, 1096 (2006). http://dx.doi.org/10.1590/ S0103-50532006000600006.

[8] Friel JJ, Mehta S, Mitchell GD, Karpinski JM. Direct observation of the mesophase in coal. Fuel, 59, 610 (1980). http://dx.doi. org/10.1016/0016-2361(80)90121-0.

[9] Brooks JD, Taylor GH. The formation of some graphitizing carbons. In: Walker PL, Radovic LR, eds. Chemistry and Physics of Carbon Vol 4, Marcel Dekker, New York, 243 (1965).

[10] Nelson HW. Petroleum coke handling problems. Ind Eng Chem Prod Res Dev, 9, 176 (1970). http://dx.doi.org/10.1021/ i360034a011.

[11] Sawarkar AN, Pandit AB, Samant SD, Joshi JB. Petroleum residue upgrading via delayed coking: a review. Can J Chem Eng, 85, 1 (2007). http://dx.doi.org/10.1002/cjce.5450850101.

[12] Mochida I, Korai Y, Wang YG, Hong SH. Preparation and Properties of Mesophase Pitches. In: Pierre D, ed. Graphite and Precursors, Gordon and Breach, Amsterdam, The Netherlands, 221 (2001).

[13] Lewis IC. Chemistry of carbonization. Carbon, 20, 519 (1982). http://dx.doi.org/10.1016/0008-6223(82)90089-6.

[14] Mochida I, Oyama T, Fei Y, Furuno T, Korai Y. Optimization of carbonization conditions for needle coke production from a lowsulphur petroleum vacuum residue. J Mater Sci, 23, 298 (1988). http://dx.doi.org/10.1007/BF01174069.

[15] Marsh H, Dachille F, Melvin J, Walker PL, Jr. The carbonisation of anthracene and biphenyl under pressures of $300 \mathrm{MNm}$ (3 kbar). Carbon, 9, 159 (1971). http://dx.doi.org/10.1016/00086223(71)90128-X.

[16] Heavy Oil Division. Refining section of the Japan Petroleum Institute. J Jpn Petrol Inst, 24, 44 \& 54 (1981).

[17] Jacob RR. Coke quality and how to make it. Hydrocarbon Process, 9, 132 (1971).

[18] Wang G, Eser S. Molecular composition of the high-boiling components of needle coke feedstocks and mesophase development. Energy Fuels, 21, 3563 (2007). http://dx.doi.org/10.1021/ ef0605403.

[19] Eser S, Jenkins RG. Carbonization of petroleum feedstocks II: Chemical constitution of feedstock asphaltenes and mesophase development. Carbon, 27, 889 (1989). http://dx.doi. org/10.1016/0008-6223(89)90039-0.

[20] Tano T, Oyama T, Oda T, Fujinaga I, Hashisaka H. Process for producing needle coke for graphite electrode and stock oil composition for use in the process. European Patent EP2336267 A1 (2011).

[21] Tano T, Oyama T, Oda T, Fujinaga I, Hashisaka H. Process for producing needle coke for graphite electrode and stock oil composition for use in the process. US Patent US20110186478 A1 (2011).

[22] Mochida I, Oyama T, Korai Y, Fei YQ. Study of carbonization using a tube bomb: evaluation of lump needle coke, carbonization mechanism and optimization. Fuel, 67, 1171 (1988). http://dx.doi. org/10.1016/0016-2361(88)90033-6.

[23] Song S, Cheng X. The influence of alkyl group on needle coke formation. Adv Mater Res, 335-336, 1433 (2011). http://dx.doi. org/10.4028/www.scientific.net/AMR.335-336.1433.

[24] Speight JG. The Chemistry and Technology of Petroleum, Marcel Dekker, New York, 200 (1980).

[25] Dickakian G. Process for deasphaltenating cat cracker bottoms and for production of anisotropic pitch. US Patent US4427531 A (1984).

[26] Eser S, Jenkins RG. Carbonization of petroleum feedstocks I: Relationships between chemical constitution of the feedstocks and mesophase development. Carbon, 27, 877 (1989). http://dx.doi. org/10.1016/0008-6223(89)90038-9.

[27] Mochida I, Korai Y, Oyama T, Nesumi Y, Todo Y. Carbonization in the tube bomb leading to needle coke: I. Cocarbonization of a petroleum vacuum residue and a FCC-decant oil into better needle coke. Carbon, 27, 359 (1989). http://dx.doi.org/10.1016/00086223(89)90067-5.

[28] Mochida I, Korai Y, Fujitsu H, Oyama T, Nesumi Y. Evaluation of several petroleum residues as the needle coke feedstock using a tube bomb. Carbon, 25, 259 (1987). http://dx.doi.org/10.1016/00086223(87)90124-2.

[29] Nesumi Y, Oyama T, Todo Y, Azuma A, Mochida I, Korai Y. Properties of fluid catalytic cracking decant oils of different origins in their single carbonization and cocarbonization with a petroleum vacuum residue. Ind Eng Chem Res, 29, 1793 (1990). http://dx.doi. org/10.1021/ie00105a009.

[30] Mochida I, Oyama T, Korai Y. Formation scheme of needle coke from FCC-decant oil. Carbon, 26, 49 (1988). http://dx.doi. org/10.1016/0008-6223(88)90008-5.

[31] Park Y, Korai Y, Mochida I. Preparation of anisotropic mesophase pitch by carbonization under vacuum. J Mater Sci, 21, 424 (1986). http://dx.doi.org/10.1007/BF01145504.

[32] Mochida I, Marsh H. Carbonization and liquid-crystal (mesophase) development. 11. The co-carbonization of low-rank coals with modified petroleum pitches. Fuel, 58, 797 (1979). http://dx.doi. org/10.1016/0016-2361(79)90185-6.

[33] Mochida I, Ando T, Maeda K, Takeshita K. Catalytic carbonization of aromatic hydrocarbons-VII. Carbonization mechanism of heterocyclic nitrogen compounds catalyzed by aluminum chloride. Carbon, 16, 453 (1978). http://dx.doi.org/10.1016/00086223(78)90092-1.

[34] Mochida I, Nakamura EI, Maeda K, Takeshita K. Carbonization of aromatic hydrocarbons-IV: Reaction path of carbonization catalyzed by alkali metals. Carbon, 14, 123 (1976). http://dx.doi. org/10.1016/0008-6223(76)90121-4.

[35] Nesumi Y, Todo Y, Oyama T, Mochida I, Korai Y. Carbonization in the tube bomb leading to needle coke: II. Mechanism of cocarbonization of a petroleum vacuum residue and a FCC-decant oil. Carbon, 27, 367 (1989). http://dx.doi.org/10.1016/00086223(89)90068-7.

[36] Marsh H, Walker PL. The formation of graphitizable carbon via mesophase: chemical and kinetic considerations. In: Walker PL, Jr., Thrower PA, eds. Chemistry and Physics of Carbon Vol 15, 
Marcel Dekker, New York, 229 (1979).

[37] Mochida I, Amamoto K, Maeda K, Takeshita K. Quantitative description and modification of cocarbonization compatibility of pitch fractions. Fuel, 57, 225 (1978). http://dx.doi.org/10.1016/00162361(78)90120-5.

[38] Korai Y, Mochida I. Co-carbonization processes of a petroleum asphalt and coal-derived liquids: an approach to co-carbonization compatibility. Fuel, 62, 893 (1983). http://dx.doi.org/10.1016/00162361(83)90155-2.

[39] Mochida I, Korai Y, Fei YQ, Oyama T. Optimum carbonization conditions needed to form needle coke. Oil Gas J, 86, 73 (1988).

[40] Kuchhal YK. Feasibility of needle coke production in India. Res Ind, 27, 30 (1982).

[41] Didchenko R, Lewis IC. Method of forming an electrode from a sulfur containing decant oil feedstock. US Patent US5167796 A (1992).

[42] Hsu HL. Non-puffing petroleum coke. US Patent US4334980 A (1982).

[43] Marsh H, Foster JM, Hermon G, Iley M, Melvin JN. Carbonization and liquid-crystal (mesophase) development. Part 3. Co-carbonization of aromatic and heterocyclic compounds containing oxygen, nitrogen and sulphur. Fuel, 52, 243 (1973). http://dx.doi. org/10.1016/0016-2361(73)90052-5.

[44] Weinberg VL, Sadeghi MA, Yen TF. Method of optimizing mesophase formation in graphite and coke precursors. US Patent 4773985 (1988).

[45] Obara T, Yokono T, Sanada Y, Marsh H. Carbonization behaviour of pitch in the presence of inert material. Fuel, 64, 995 (1985). http://dx.doi.org/10.1016/0016-2361(85)90157-7.

[46] Marsh H, de Lopez H, Qian Z. Co-carbonization of Ashland A240 petroleum pitch with alkali metal carbonates and hydroxides. Fuel, 63, 1594 (1984). http://dx.doi.org/10.1016/0016-2361(84)902333.

[47] Wang YG, Korai Y, Mochida I, Nagayama K, Hatano H, Fukuda $\mathrm{N}$. Modification of synthetic mesophase pitch with iron oxide, Fe2O3. Carbon, 39, 1627 (2001). http://dx.doi.org/10.1016/S00086223(00)00281-5.

[48] Boudou JP, Begin D, Alain E, Furdin G, Mareche JF, Albiniak A. Effects of $\mathrm{FeCl}_{3}$ (intercalated or not in graphite) on the pyroly- sis of coal or coal tar pitch. Fuel, 77, 601 (1998). http://dx.doi. org/10.1016/S0016-2361(97)00143-9.

[49] Song H, Chen X, Chen X, Zhang S, Li H. Influence of ferrocene addition on the morphology and structure of carbon from petroleum residue. Carbon, 41, 3037 (2003). http://dx.doi.org/10.1016/ S0008-6223(03)00430-5.

[50] Ramos-Fernandez JM, Martinez-Escandell M, Reinoso FR. Preparation of mesophase pitch doped with $\mathrm{TiO} 2$ or $\mathrm{TiC}$ particles. J Anal Appl Pyrolysis, 80, 477 (2007). http://dx.doi.org/10.1016/j. jaap.2007.06.005.

[51] Gimaev RN, Valyavin GG, Voloshin ND, Fryazinov VV, Slutskaya SM. Expansion of resources and improvement of quality of petroleum electrode coke. Chem Technol Fuels Oils, 15, 478 (1980). http://dx.doi.org/10.1007/BF00723697.

[52] Mochida I, Korai Y, Oyama T. Semi-quantitative correlation between optical anisotropy and CTE of needle-like coke grains. Carbon, 25, 273 (1987). http://dx.doi.org/10.1016/00086223(87)90126-6.

[53] Mochida I, Korai Y, Nesumi Y, Oyama T. Carbonization in a tube bomb. 1. Carbonization of petroleum residue into a lump of needle coke. Ind Eng Chem Prod Res Dev, 25, 198 (1986). http://dx.doi. org/10.1021/i300022a013.

[54] Tomkow K, Siemieniewska T, Czechowski F, Jankowska A. Formation of porous structures in activated brown-coal chars using $\mathrm{O} 2, \mathrm{CO} 2$ and $\mathrm{H} 2 \mathrm{O}$ as activating agents. Fuel, 56, 121 (1977). http://dx.doi.org/10.1016/0016-2361(77)90129-6.

[55] Mochida I, Korai Y, Wang MZ. Effects of preheat-treatment on the bulk density of semi-cokes produced from petroleum and coal derived pitches. J Fuel Soc Jpn, 63, 41 (1984). http://dx.doi. org/10.3775/jie.63.41.

[56] Mochida I, Oyama T, Korai Y. Improvements to needle-coke quality by pressure reductions from a tube reactor. Carbon, 26, 57 (1988). http://dx.doi.org/10.1016/0008-6223(88)90009-7.

[57] Jieming X, Guo F, Minglan G, Yanqing Z. Preparation of high quality needle coke from FCC decant oil. Lect Notes Inf Technol, 22, 6 (2012).

[58] Eser S. Mesophase and pyrolytic carbon formation in aircraft fuel lines. Carbon, 34, 539 (1996). http://dx.doi.org/10.1016/00086223(96)00007-3. 